\title{
DEFENSA DE PALAMEDES DE GORGIAS: PLURALIDADES DEL YO QUE ENUNCIA EN LA ETOPEYA GORGIANA
}

\author{
Ivana Selene Chialva*
}

RESUMEN: La Defensa de Palamedes es un texto ficticio de apología judicial, exponente del género epidíctico, escrito aproximadamente en el año 411 a.C. La condición retórico-escolar del texto está dada en el título ya que constituye un recurso avant la lettre que, en los Progymnásmata de época imperial, será definido y enseñado bajo el nombre de un ejercicio particular: etopeya (o prosopopeya), i.e. un discurso apropiado para un personaje, histórico o ficticio, escrito en primera persona y elaborado en léxico, tema y estilo de acuerdo a las características del personaje. Este recurso es el que subyace en los parlamentos del teatro clásico, en las apologías forenses de los logógrafos y en todo intento de construcción de la palabra de un yo por otro yo. Nuestra intención en este trabajo es explorar la construcción de la etopeya en el pliegue enunciativo del yo que habla, Palamedes, detrás del cual se deja leer el yo Gorgias, y advertir las múltiples direcciones de interpretación que ese pliegue genera al poner en diálogo el texto sofístico con sus con-textos filosóficos y, puntualmente, trágicos.

PALABRAS CLAVE: Apologia; Gorgias; etopeya; Palamedes.

\section{DEFENSE OF PALAMEDES BY GORGIAS: PLURALITIES OF THE "I" ENUNCIATOR IN THE GORGLAN ETHOPOEIA}

* Investigadora Asistente del Conicet. Profesora Adjunta de Literaturas griega y latina de la Universidad Nacional del Litoral (Santa Fé, Argentina).

\begin{abstract}
Defense of Palamedes is a fictional text of judicial apology that belongs to the epideictic genre, written about in the year 411 a.C. The rhetoric-scholar condition of the text is evident from the title since it is a procedure avant la lettre that will be defined and taught, in Progymnasmata of Imperial age, as ethopoeia (or prosopopoeia): the words of a historic or fictional character, written in first person, elaborated in lexicon, general subject and style according to the traits of this character. This exercise underlies multiple speeches: the parliaments of classic drama, the forensic apologies of the logographers and all imitation of the words of one "I" by other "I". In this article we will explorer the ethopoeia's construction in the enunciative fold of the "I" enunciator, Palamedes, behind which
\end{abstract}


is the "I" enunciator Gorgias. And we will analyze the multiple interpretations of that fold by putting the sophistic text into dialogue with the philosophic and tragic contexts.

KEYWORDS: Apology; Gorgias; ethopoeia; Palamedes.

\section{INTRODUCCIÓN}

$\mathrm{U}$

n lugar común a la hora de clasificar Defensa de Palamedes (Pal.), Encomio de Helena (Hel.) e, incluso, Sobre el no ser es considerarlos ejercicios retóricos: textos producidos artificialmente para funcionar como modelos de imitación de recursos, mediante la copia y la memorización, en la educación sofística. Ese rótulo es, sin duda, acorde a los textos, especialmente en los dos primeros casos ya que la defensa y el encomio constituían tipologías retóricas de dos de los tres géneros que, más tarde, delimitará Aristóteles: el judicial y el epidíctico. Un elemento a revisar, en cambio, es que esa calificación ha funcionado como un signo distintivo o, incluso, de exclusión para designar todo lo que estos textos no son: no son ciertamente filosofía in stricto sensu, ni retórica política, ni poesía dramática (i.e. literatura). De allí que parte de la crítica los definiera como "meros" ejercicios retóricos, aunque es claro que el influjo de esos géneros mayores está presente en el corpus gorgiano. Y si bien, en las últimas décadas, ese juicio ha sido discutido en relación al Sobre el no ser y el Encomio en valiosos estudios sobre la sofística, ${ }^{1}$ no ha sucedido lo mismo ni en la misma medida con el Palamedes, texto menos frecuentado por los especialistas. Un claro ejemplo del lugar periférico de la Defensa dentro de los estudios filosóficos y literarios e, incluso, dentro del corpus gorgiano, es que mientras en los últimos 5 años, y como repercusión de las investigaciones académicas, se han realizado, en Argentina, traducciones de Sobre el no ser (Díaz; Spangenberg, 2011) y del Encomio (Davolio; Marcos, 2011; Chialva; Bonacossa; Casís; Omar, 2013), aún no contamos con una traducción de la Defensa al español rioplatense que incorpore esas proyecciones críticas. Esta ausencia es sintomática si consideramos, con Even Zohar (1990), que las obras traducidas en una lengua se relacionan entre sí por la elección que de los textos de origen hace la cultura receptora y por la relación entre esos principios de selección y los sistemas de conocimientos locales (académicos, literarios, artísticos, etc.), que movilizan lecturas e interpretaciones y, por lo tanto, orientan esa selección. Nuestro objetivo, aquí, es presentar algunos problemas teóricos que se derivan de esa condición retórico-escolar del texto e interpretarlos en diálogo con su con-texto, esto es, con-textos filosóficos, dramáticos y políticos de la Atenas de finales del s. V a.C.

\footnotetext{
${ }^{1}$ La bibliografía especializada sobre retórica y sofística es muy extensa. Citamos, entre los más relevantes, los estudios de Untersteiner (1949, 1967), McComiskey (1963), de Romilly (1988), Cassin (1986, 1995), Worthington (1994, 2007), Wardy (1996), Gagarin (1995, 1997, 2001); Mazzara (1999), Consigny (2001), Giombini (2012). Esta renovación de lecturas críticas en el ámbito internacional ha suscitado nuevos abordajes también en las investigaciones en Argentina. Cabe mencionar, especialmente, los trabajos de: Castello; Mársico (2005), Davolio; Marcos (2011), Livov; Spangenberg (2012), Spangenberg (2011), M. Divenosa (2011), L. Álvarez (2012), entre otros. En Brasil, cabe destacar la traducción e interpretación del Tratado sobre el no ser y Defensa de Palamedes de la Tesis Doctoral de Martínez (2008), quien incorpora la bibliografía crítica actualizada para abordar ambos textos gorgianos.
} 


\section{EL EJERCICIO DE LA ETOPEYA}

Un punto de partida para presentar algunas problemáticas derivadas de los trabajos en torno a la Defensa de Palamedes es partir de la traducción del título: el manuscrito A (cod. Crippsianus, Burney MS95, ff. 154 v.159r, s. XIII), única fuente medieval que ha conservado el

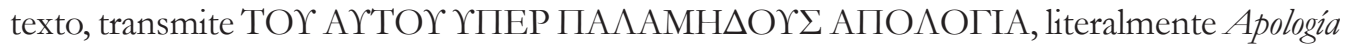
de Palamedes, del mismo [autor]. Conviene señalar dos cuestiones: en primer lugar, ¿Apología o Defensa? Más allá de la elección, aparentemente intranscendente, entre la transcripción del término griego o su traducción al término jurídico, la consecuencia de esa elección es teórico-interpretativa. Las Apologías filosóficas de Platón y de Jenofonte o, incluso, la Apología retórico-judicial de Antifonte han sido leídas de forma comparada, cotejando sus modos de argumentación y su crítica a los hechos históricos que las motivan: i.e. la refutación de una acusación religiosa o política mediante el procedimiento retórico basado en el eikós. ${ }^{2} \mathrm{La}$ Apología gorgiana, por su parte, parece no formar serie con los textos de su género, debido a su marcada tendencia epideíctica. Así, abordada generalmente desde su constructo retórico o a partir de la relación intertextual con el diálogo platónico, los mecanismos argumentativos que en este último texto son considerados funcionales a la teorización filosófica sobre el concepto de verdad, en el texto sofístico son acotados a una destreza o habilidad retórica por sí misma: i.e. un paígnion (citando el célebre término final del Encomio de Helena). Un segundo aspecto a destacar del título es la doble referencia a sujetos de la enunciación, en niveles diferentes del texto: Defensa de Palamedes, ${ }^{3}$ del mismo [autor]. En el cuerpo del texto, esa doble instancia

\footnotetext{
${ }^{2}$ Gagarin, en un artículo del año 2002, compara la muerte de Antifonte y la de Sócrates y la construcción de sus respectivas Apologías por el propio Antifonte y por Platón. Muestra el autor cómo, más allá de los paralelismos históricos entre los dos personajes (ambos levantan sospechas por sus actividades intelectuales, ambos hacen sus discursos de defensa, ambos se resisten a elegir el exilio, ambos son condenados a muerte, etc.) existen paralelismos en los argumentos de defensa que el retórico y el filósofo exponen ante sus jueces. Más allá del estado fragmentario de la Apología antifontea, el crítico da cuenta de los puntos de conexión entre ambos discursos para plantear la hipótesis de la posible influencia que la Apología de Antifonte pudo haber ejercido sobre la construcción de la Apología platónica. Hasta donde sabemos, no ha sido planteada aún una lectura en paralelo de las coincidencias argumentativas de ambas defensas con la Apología gorgiana, que sería, según la fecha de datación, anterior a ambos discursos. Sí se ha vinculado la Defensa con las Tetralogías de Antifonte, y nuevamente en este tema el debate en torno a la datación y las influencias de uno sobre otro aún son un punto de discusión entre los especialistas (Cassin, 1995, 165ss; Martinez, 2008, 101-3).

${ }^{3}$ Respecto del título, otro elemento interesante que podría remitir al doble nivel enunciativo, ligado

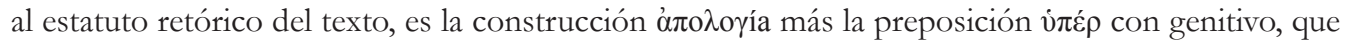
puede traducirse también como Defensa de parte de Palamedes, Defensa en nombre de Palamedes o En defensa de Palamedes, de forma similar a los títulos de las obras de los oradores atenienses del siglo IV a.C.: Lisias (ПЕР TOY EPATO $\triangle \Theta \mathrm{ENO}^{2}$ ФONOY АПО $А$ ОГIА, En defensa de la muerte de Eratóstenes; ҮПEP KA $\Lambda$ IOY IEPO $\Upsilon \Lambda$ IA $\Sigma$ АПО $\Lambda$ ОГIA, En defensa de Calias por sacrilegio, entre otros) e

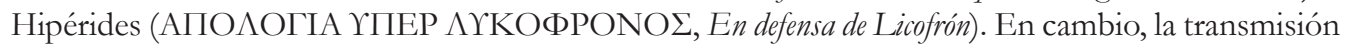
de los títulos que tenemos de las defensas de Platón y Antifonte es АПО ОГІА $\Sigma \Omega$ KРАТОГ $\Sigma$,
} 
se vuelve menos perceptible, debido a que hay un sujeto de la enunciación explícito, que es Palamedes, detrás del cual se percibe otro sujeto de la enunciación tácito, Gorgias. ${ }^{4}$ Este yo sofista que escribe la defensa de otro yo para un juicio es, por cierto, una actitud afín a la tarea de los logógrafos, quienes componían discursos que buscaban la eficacia argumentativa y la pertinencia del estilo retórico con el carácter y la procedencia social de su cliente. En el texto gorgiano, ese desdoblamiento del yo que enuncia sobre un personaje mítico del Ciclo Troyano hace explícita la modalidad ficcional del texto y, por ende, su función escolar. Al igual que la prosa poética, trabajada por los schémata gorgíeia (paralelismo, antítesis, quiasmo, etc), que evidencia la artificialidad del discurso, supuestamente improvisado, del héroe épico. De modo que el título ya declara la condición retórico-escolar de un ejercicio que, en los Progymnásmata de época imperial, será definido y enseñado bajo el nombre de etopeya (o prosopopeya), i.e. un discurso apropiado para un personaje, ya sea histórico o ficticio, escrito en primera persona y elaborado en léxico, forma, tema y estilo de acuerdo a las características del personaje. ${ }^{5}$ En la identificación o la diferencia de esas dos instancias de enunciación es en donde se juegan las múltiples interpretaciones del texto sofístico. Expondremos brevemente algunas de ellas.

\section{DEFENSA DE PALAMEDES Y SU CON-TEXTO}

Entonces, la Defensa de Palamedes es un texto ficticio de apología judicial, exponente del género epidíctico, escrito en algún momento entre el año 427 a.C., fecha de la llegada de Gorgias a Atenas, y la fecha de su muerte, en el 380 a.C. aproximadamente (Martínez, 2008, 80; Giombini, 2012). Algunos estudiosos han acotado ese amplio margen temporal, proponiendo el año 411 a.C. como término ante quem (Clúa Serena, 1985), lo que haría al texto sofístico anterior a las tres Apologías mencionadas de Antifonte, Platón y Jenofonte. Su función escolar y su ascendencia sobre las defensas judiciales podrían llevar a un análisis en profundidad sobre las posibles relaciones entre la obra gorgiana y las dos primeras obras

con genitivo subjetivo, aunque también debe entenderse como genitivo objetivo en tanto es objeto del decir de otro autor, más allá de que ambos textos filosóficos, por su carácter biográfico, busquen velar esta última instancia.

${ }^{4}$ Nos referimos a Gorgias no como el autor, sujeto real histórico, sobre el cual se saben pocos datos ciertos, sino a Gorgias sofista en tanto sujeto de la enunciación de otros textos, transmitidos de manera directa o indirecta bajo su nombre, y que conforma un horizonte de lectura que proyecta sus sentidos hacia el propio texto de la Defensa.

${ }^{5} \mathrm{Si}$ bien los manuales de ejercicios escolares (escritos por maestros de retórica para otros maestros de retórica) se generalizan en época imperial, ya en época helenística hay múltiple evidencia de antologías escolares de ejercicios progymnasmáticos, es decir, de colecciones de ejercicios concretos de etopeyas, ekphráseis, encomios, etc. Ascendiendo cronológicamente en la educación progymnasmática, Eurípides no sólo se convierte en modelo textual de dicha formación retórica en tiempos helenísticos sino que su poesía retorizante podría ser ya resultado de dicha formación (Fernández Delgado; Pordomingo, 2016). En ese caso, los ejercicios escolares gorgianos son, indudablemente, antecedentes concretos de la educación progymnasmática posterior y Defensa de Palamedes representa, en esta línea, un ejercicio de etopeya avant la lettre. 
de esa serie. Pero es otra influencia la que nos interesa desatacar en la composición del Palamedes: aquella que lo liga estrechamente con la poesía anterior, en especial, con la poesía trágica. Al respecto, las metamorfosis del relato mítico sobre el personaje son significativas para reflexionar en torno a esa proximidad genérica y sus implicancias conceptuales en la pieza sofística.

En principio, Palamedes es un héroe épico cuyas hazañas figuraban en los Cantos Ciprios y en los Nóstoi aunque, como es sabido, su nombre no es mencionado en ninguno de los poemas homéricos, hecho que desde la propia antigüedad dio lugar a interpretaciones y en torno al silencio de Homero (Vellay, 1956; Clúa Serena, 1985). Su condición de héroe culturizador fue transmitida por la poesía arcaica, especialmente Estesícoro y Píndaro, pero es en época clásica cuando el tema de su muerte injusta en un juicio cobra un verdadero desarrollo poético no atestiguado antes. En los tiempos en que Gorgias escribe su defensa, el motivo mítico del juicio de Palamedes estaba muy presente en el imaginario de los polítai atenienses. Sabemos, por los fragmentos conservados, que los tres trágicos, Esquilo, Sófocles y Eurípides, escribieron un drama titulado Palamedes, y que en todos los casos, la acción dramática se centraba en el juicio al héroe por una falsa acusación de traición, tramada por Odiseo, en donde los jefes aqueos, y en especial Agamenón, condenaban a muerte y lapidaban a su mayor benefactor. Los críticos coinciden en que ciertos rasgos comunes debieron haber articulado las tres obras homónimas: 1. presentar a Palamedes como un héroe culturizador ( $\pi \alpha ́ v \sigma o \varphi o \varsigma$ es el adjetivo usado por los tres trágicos); 2. detallar la lista de sus inventos; 3. representar un agón judicial de acusación y defensa donde el propio héroe u otro en su nombre habría recusado los argumentos de la acusación (Romero Mariscal, 2004). Más allá de las hipótesis de la crítica sobre los argumentos de cada una de las obras, lo que nos interesa destacar aquí es la estrecha conexión entre la pieza gorgiana y el género dramático en los siguientes puntos: la elección del personaje Palamedes, el episodio mítico del juicio por traición, la estructura agonal del discurso de defensa (que prevé, como supuesto, un discurso de acusación) e, incluso, la similitud del tratamiento temático del personaje, presentado como sophós y prôtos energétes, junto con la lista de sus inventos y sus beneficios para la vida civilizada y el bien común (Pal. 30; 36).

Otro punto a considerar en la relación entre el Palamedes sofístico y el Palamedes trágico es el espinoso y no resulto problema de la datación. Se sabe que la obra de Eurípides formaba parte de una Trilogía Troyana integrada por Alejandro, Palamedesy Troyanas, representada en el año 415 a.C. Muchas veces se ha destacado, en Troyanas, la crítica social implícita a la política exterior ateniense (cuyo hecho paradigmático fue la toma de la isla de Melos el año anterior). También se ha señalado su relación con la otra obra de transmisión directa de Gorgias, el Encomio de Helena, la cual ha sido datada e interpretada en relación con dicha tragedia. En el caso del Palamedes, a partir de los 40 versos conservados, se ha querido ver allí un cuestionamiento a la política interna de la ciudad de Atenas, en referencia a la persecución de intelectuales: filósofos, sofistas y rétores (Clúa Serena, 1985). Un ejemplo de dicho hostigamiento intelectual y judicial fue Protágoras, si es que el juicio tuvo lugar y aconteció, 
como se estima, en ese mismo año del 415 a.C. ${ }^{6}$ Otro ejemplo tendrá lugar en el año 411 a.C. con el juicio y condena a muerte del orador y logógrafo Antifonte. Y, finalmente, el caso más célebre: el juicio y condena de Sócrates en el 399 a.C. La proximidad entre la temática trágica y estos hechos políticos llevó incluso a D. E. Sutton a afirmar que detrás del Palamedes euripídeo se planteaba el caso de Protágoras y su conflicto con la justicia de Atenas. ${ }^{7}$ Más allá de la arriesgada identificación con una figura histórica, las lecturas coinciden en el tono reprobatorio de Eurípides, quien expondría en esa tragedia su desencanto ante el ideal de progreso y de búsqueda del bien común que había alimentado el imaginario cívico y cultural de la pólis (Clúa 1985; 2013). Aquellos que educaron a los ciudadanos mueren a instancias de éstos. Si mantenemos el año 411 a.C. como término ante quem para la Defensa gorgiana, se acentúa aún la cercanía entre la pieza trágica y la sofística en relación con los juicios a figuras representativas de la sophía, especialmente una sophía relativa al lógos.

Sin buscar resolver aquí el problema de la datación, sí nos interesa marcar esta proximidad temporal y textual entre las obras para una interpretación del Palamedes gorgiano y sus rasgos compositivos de héroe trágico. Por definición genérica, el héroe trágico es aquel personaje que gracias a su poder o su conocimiento se halla en el momento de mayor fortuna y que, por un exceso de esa misma cualidad, comete un error. La hipótesis no es nueva, ya había sido planteada por Untersteiner $(1967,201-262)$ quien reconoció la gnoseología trágica de Gorgias en la imposibilidad de demostrar, a través del lógos, la verdad. Mediante el análisis de varios pasajes de la obra, el autor explica en qué consiste el error trágico del héroe: Palamedes cree que puede mostrar la verdad con su argumentación y, a la inversa, refutar la falsedad de la acusación hecha por Odiseo. Los parágrafos 5, 24 y 29 son claves al respecto:

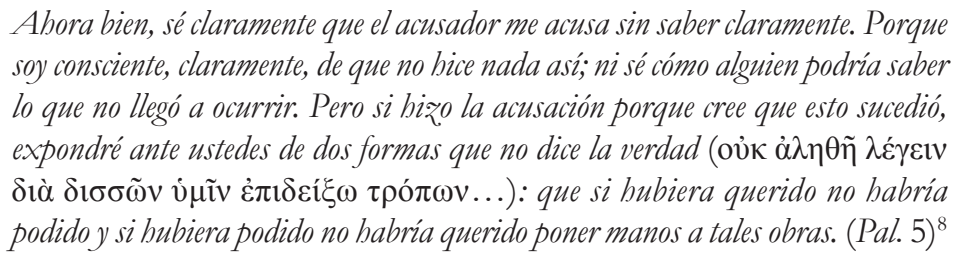

En realidad, es evidente que no sabes las cosas de las que me acusas. Entonces, lo

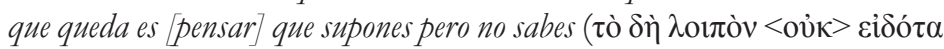
$\sigma \varepsilon \delta \mathrm{o} \xi \alpha ́ \zeta \varepsilon(v)$. Y aún así, el más arriesgado de todos los hombres, ¿confiando en

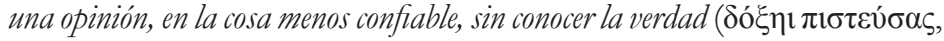

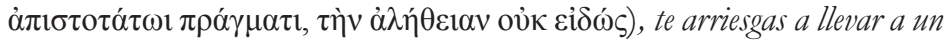
hombre a juicio con pena de muerte? ¿Sabes con certeza que realizó un hecho semejante? Ahora bien, sin duda, es común a todos opinar sobre todo y, en eso,

\footnotetext{
${ }^{6}$ Las fuentes antiguas son ambiguas con respecto a la concreción o no en Atenas de un juicio al filosófo. De época imperial, Filóstrato en su Vidas de los sofistas (10) ya trasmite las dos versiones: 1. Protágoras huye de Atenas después de la sentencia adversa en un juicio; 2 . después de una votación en su contra, pero sin juicio.

${ }^{7}$ D.E Sutton, Two lost plays of Euripides, New York, (1987: p. 112, citado por Woodford, 1994: p. 164).

${ }^{8}$ La traducción del texto gorgiano es nuestra.
} 
[no] eres en absoluto más sabio que los otros. Pero no se debe confiar en los que opinan sino en los que saben, ni juzgar que [es] más confiable la opinión que la

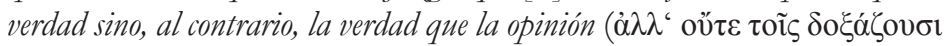

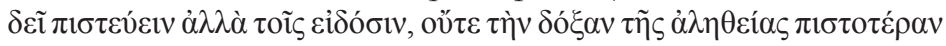

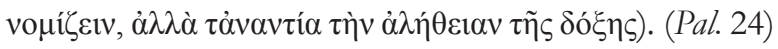

Entonces, lo primero, lo segundo y lo más importante es que de principio a fin, en todos los ámbitos, mi vida pasada está libre de errores, limpia de toda acusación. Porque ante ustedes nadie podría haber pronunciado sobre mi una acusación

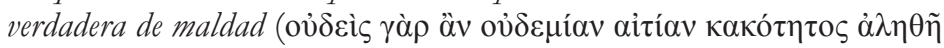

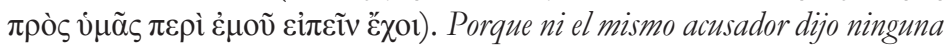

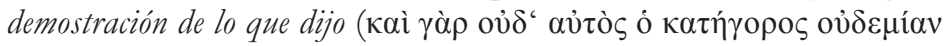

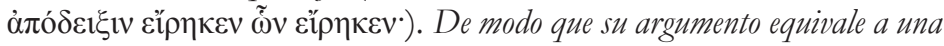

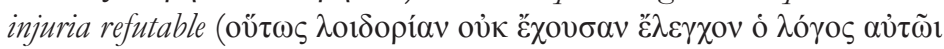

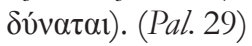

Así, todo el desarrollo argumentativo busca la legitimación de un tipo de saber sobre lo que es (o sobre lo acontecido), demostrable por un lógos verdadero, frente a un lógos sobre lo que no es (porque no sucedió), falso, engañoso, y por ende, refutable. En esta construcción gnoseológica antitética entre ser-no ser, verdad-falsedad, saber-opinión, se han basado las lecturas que leen en boca de Palamedes los principios rectores de la filosofía ontológica de Parménides. De esa concepción binaria se deriva la acción todopoderosa del lógos como camino (la metáfora es parmenídea y gorgiana) a la verdad. No obstante, después de todo el constructo de veridicción apagógica de su Defensa, Palamedes reconoce que no es posible, a través de las palabras, hacer que la verdad de los hechos resulte clara y pura a los oyentes (Pal. 35):

Entonces, si fuera posible que a través de las palabras la verdad de los hechos

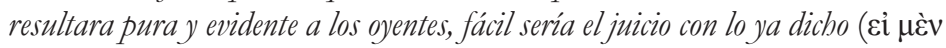

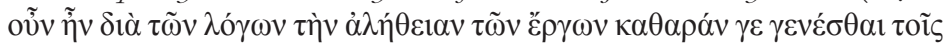

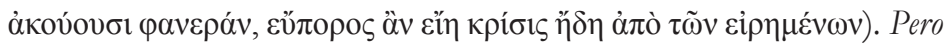
como no es así, mientras me custodian, esperen más tiempo y elaboren un juicio

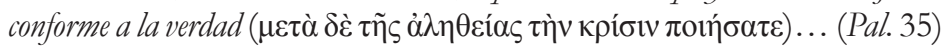

Dice Untersteiner: la parola non può dimostrare il vero: questo è un puro ideale $(1967,207)$. El camino que conduce de la verdad del ser a la verdad de los discursos queda, de pronto, suspendido. Según el crítico italiano, esta inflexión interna de la defensa haría del Palamedes gorgiano una puesta en escena (en el sentido dramático) del conflicto de la tercera cláusula del tratado Sobre el no ser. 1 . nada es; 2 , si es, no es cognoscible, 3. si es y es cognoscible, no se puede comunicar a otros. Así, de los tres niveles implicados en las tesis gorgiana (el ontológico, el gnoseológico y el lingüístico), Palamedes está atrapado en la escisión entre el plano gnoseológico y lingüístico del ser. Es allí, en el parágrafo 35 donde el yo sofista se filtra en la palabra del yo Palamedes para abrir un espacio de cuestionamiento dentro del propio lógos que afirma su saber. El texto, en un pliegue, dice a la vez dos cosas: la posibilidad e imposibilidad de decir la verdad. En esa tensión, creemos, existen otras instancias de problematización 
sofística del discurso filosófico palamediano. Una de ellas reside, precisamente, en esa categoría de verdad, enunciada a lo largo del texto en singular, bajo un concepto aparente de unidad. La Defensa sostiene, como garantía de sí misma, el vínculo entre la verdad de los hechos, la verdad del conocimiento del que enuncia y la verdad de los argumentos, y esas verdades pueden corresponderse y colaborar entre sí. El texto insiste en la posibilidad de decir la verdad y mostrarla con argumentos, es decir, de demostrar lógicamente lo que es posible y refutar lo que no lo es:

A no ser que aprenda algo de la propia verdady de la necesidad actual, maestras

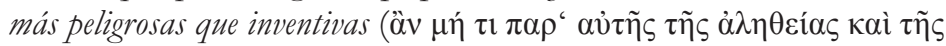

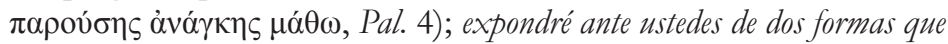

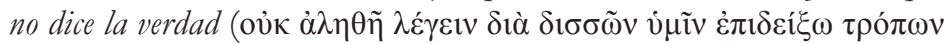
Pal. 5); Digo la verdad (à $\lambda \eta \theta \tilde{\eta} \lambda \dot{\varepsilon} \gamma \omega$, Pal. 15); el argumento es novedoso pero no verdadero (каıvò

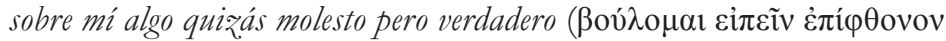
$\mu \dot{\varepsilon} v$ à $\lambda \eta \theta \grave{\varepsilon} \varsigma \delta \dot{\varepsilon}$, Pal. 28); es preciso que yo salga de esta acusación con lo que claramente es justo, enseñando lo verdadero, sin engaños ( $\delta 1 \delta \alpha \dot{\xi} \alpha v \tau \alpha \tau \dot{\alpha} \lambda \eta \theta \dot{\varepsilon} \varsigma$,

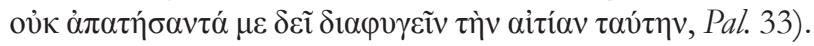

El problema en torno al carácter transitivo de la verdad es tratado en un nivel exponencial en la versión del mito que elige o crea Gorgias, donde a diferencia de la obra de Eurípides (cuya hypóthesis se toma de la Fábula 105 de Higino) había pruebas "plantadas" por Odiseo: una carta dirigida a Palamedes por Príamo (escrita por el propio Odiseo) donde le ofrecía oro por traicionar al ejército aqueo y una cantidad de oro (la misma de la carta) enterrada bajo la tienda del héroe. En la variante del relato de la Defensa, no hay pruebas y no hay testigos: la veridicción de los argumentos se da por su demostración lógica. Se trata de lo que es dynatós, posible (como variante del eikós, lo verosímil). Toda la argumentación apagógica de la pieza concluye en demostrar qué es posible hacer o desear. No obstante, en el mismo parágrafo 35 señalado por Unstersteiner, después de escindir esa unidad entre hechos-saber-lógos, Palamedes apela a los jueces a hacer una sentencia conforme a la verdad

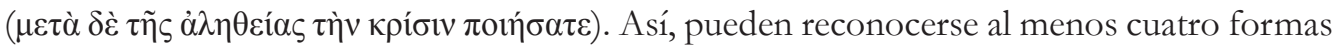

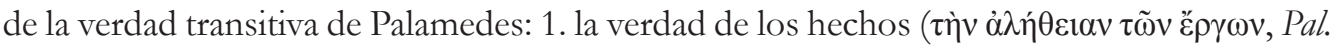
35); 2. la verdad del conocimiento ( $\sigma \alpha \varphi \tilde{\omega} \varsigma$ oĩ $\alpha \alpha$, Pal. 5); 3. la verdad de los discursos ( $\dot{\alpha} \lambda \eta \theta \tilde{\eta}$

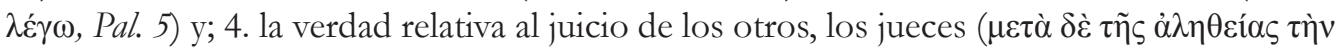

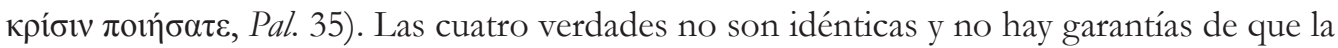
primera pueda ser aprehendida por la segunda, manifestada claramente por la tercera, y regir, la cuarta, los juicios y hechos de los otros. No obstante, Palamedes insiste en la confianza de ese vínculo transitivo. De allí el vocabulario que se despliega en torno al verbo $\delta$ cí́vvu y sus compuestos: en primera persona $\dot{\varepsilon} \pi \imath \varepsilon \dot{\xi} \xi \omega($ Pal. 5) y su opuesto en forma nominal adjetiva,

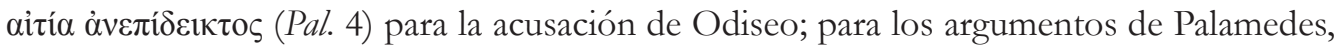
$\delta \varepsilon ́ \delta \varepsilon \imath \kappa \tau \alpha \imath$ (Pal. 21), y en referencias a los otros sujetos del discurso, el acusador y los jueces,

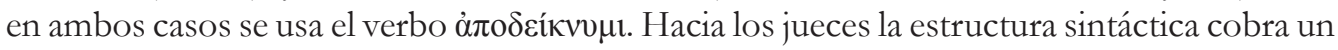
matiz recursivo que encierra la demostración lógica en el campo de la exhibición discursiva: 


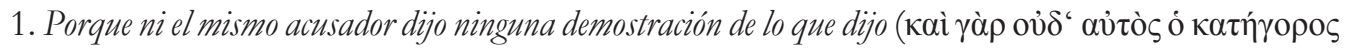

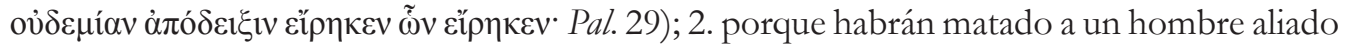
... sin haber demostrado ninguna injusticia evidente ni una acusación confiable (

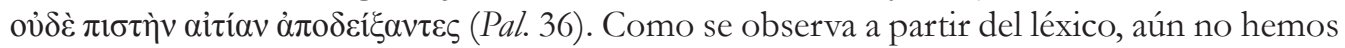
llegado a la especificación de los tres géneros retóricos propuestos por Aristóteles sino que epídeixis y apódeixis alternan en el discurso como condiciones presentes o ausentes de un decir. La demostración, las pruebas, también existen en la medida en que sean dichas y exhibidas (en el sentido epidíctico del término) con argumentos. En este sentido coincidimos con Cassin, quien afirma que en la sofística gorgiana la apódeixis es subsumida por la epídeixis (1995, 195-215) en un dominio pleno del lógos.

\section{Palamedes trágico: la CuARta PRemisa}

Pero Palamedes va más allá, no sólo puede demostrar y probar la verdad, puede

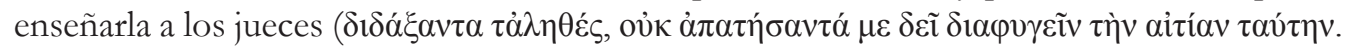
Pal. 33). El héroe cree, hasta el final de su apología, que la de-mostración de los argumentos en torno a lo que es verdadero es una herramienta confiable para el triunfo de la verdad en los espacios de resolución de conflictos de la comunidad (de guerreros, en este caso). Llegados a este punto, y como conclusión, nos gustaría sugerir aquí otra interpretación posible del error trágico de Palamedes en su confianza en el lógos: en los últimos dos parágrafos, Palamedes advierte a los jueces del error (la palabra griega es hamartía, otra referencia directa a la tragedia) que cometerán si lo condenan sin pruebas (entiéndase sin argumentos). Puede decirse que, en el desdoblamiento del yo que enuncia, donde se cruzan ecos parmenídeos y gorgianos, se da un último distanciamiento del yo sofista con relación al yo que enuncia. Ese distanciamiento es una forma de la ironía trágica: como advertencia, sospecha o incluso amenaza velada, el héroe aconseja a los jueces cuidar su fama de hombres sabios y justos, para no ser recordados como hombres injustos e infames. Ante el carácter irrefutable de la argumentación apagógica del texto, la Defensa se erige como un discurso que se sostiene como verdadero por sí mismo, que muestra, demuestra y enseña la inocencia del héroe, al punto de prever los posibles contraargumentos del acusador. El receptor no imagina, después de leerlo, el discurso de acusación de Odiseo como un lógos verdadero o sostenible, ya que se han invalidado todas las causas posibles o imaginables de traición. ${ }^{9}$

Pero el oyente-lector de ese brillante discurso sabe que ese lógos irreprochable no triunfó, que no consigue, en definitiva, su fin último. Es a partir de ese saber con-textual de la tradición mítica desde donde se lee la ironía que corroe las palabras finales del héroe. El error de Palamedes no sería únicamente gnoseológico, en el plano del conocimiento abstracto de la relación lógos-ser (de lo acontecido), sino que también es, si se quiere, pragmático-político.

\footnotetext{
${ }^{9}$ Pese a las similitudes formales y de ciertos argumentos entre ambos textos, dudamos, junto con Clúa (1985), que la acusación Contra Palamedes por traición de Alcidamante pueda ser considerada una respuesta agonal al texto de Gorgias, ya que no responde a la misma versión del relato mítico, especialmente en lo que respecta a la falta de los testigos, elemento clave en el texto gorgiano, que es modificado por Alcidamante.
} 
La Defensa de Palamedes pondría en evidencia otra dimensión del lógos, que es el lógos en su espacio de circulación de la pólis, en su agón con otros lógoi que postulan y se adjudican, con justicia o sin ella, otras verdades. En relación con otras obras del corpus gorgiano, es posible leer la Defensa como la dramatización de la tesis del parágrafo 13 del Encomio de Helena: ${ }^{10}$ el lógos es el que hace evidente las cosas que no son evidentes: la verdad de los seres, la verdad de los hechos y la verdad de los conceptos, y el dominio sobre el cual se construye el conocimiento es la dóxa. La Defensa, en tanto género judicial, estaría ligado al segundo ejemplo en particular, los agônes en los tribunales, donde un lógos puede deleitar y persuadir, escrito con arte pero no dicho con verdad. ${ }^{11}$ Puede asumirse que tal será, efectivamente, el caso del discurso del astuto Odiseo, que logrará persuadir y ganar la decisión de los jueces. Pero, en un juego conceptual sofístico, también es válida esa afirmación para el discurso del propio Palamedes, que nos persuade de su inocencia, aunque su discurso conlleva una asunción del concepto de verdad unívoca que es engañosa ${ }^{12}$. Es, precisamente, ese rasgo intransitivo de la verdad uno de los efectos de lectura que se desprende de la pieza gorgiana.

Puede decirse que la Defensa deja en suspenso una cuarta premisa derivada de la tercera del Sobre el no ser. incluso si el ser es, es cognoscible y es comunicable, no es (para decirlo con un término del ámbito legal) vinculante. Por esta razón, creemos que más que el Encomio y la Defensa deben ser considerados tanto en sus coincidencias como en sus contrates, sus refutaciones. Palamedes en su coherencia con las otras obras del corpus gorgiano se proyecta hacia un espacio diferente y puede ser leído como la performance de la antithesis de otra thésis gorgiana: la del poder omnipotente del lógos, defendida en el Encomio de Helena (Hel. 8). Ambas obras son un díptico conceptual a la manera de los díssoi lógoi, donde lo que se pone en discusión es el alcance del lógos, de la verdad y la persuasión en los agônes (poéticos, jucidiales y filosóficos) de la pólis. Asimismo, el texto conlleva tácitamente esa instancia final de la anagnórisis el héroe, cuando él mismo comprenda su error al ver que su saber no lo salvará. Por eso, la versión gorgiana del relato mítico realiza un progresivo desmonte de las asociaciones significantes que, en el relato idealizado de la pólis (un referente es Euménides de Esquilo), resguardaban a la verdad como bien supremo: los dioses, los pares de la comunidad, la justicia institucionaliza, la coherencia argumentativa de la persuasión. Cada una de esas

\footnotetext{
${ }^{10}$ Que la persuasión que llega con el lógos moldea el alma como desea, es necesario aprenderlo, en primer lugar, de los lógoi de los que estudian los astros, los cuales dóxa contra dóxa, desplazando una y produciendo otra, hacen que las cosas increíbles y no evidentes se manifiesten mediante la mirada de la dóxa. $Y$, en segundo lugar, de los necesarios agônes mediante los lógoi, en los cuales un lógos deleita a una gran muchedumbre y persuade por haber sido escrito con arte pero no dicho con verdad. Y, en tercer lugar, de las contradicciones entre los lógoi de los filósofos, a partir de las cuales también se muestra la fugacidad del conocimiento, debido a que hace mudable la creencia de la dóxa. (Chialva et all., 2013, 69).

${ }^{11}$ Nótese nuevamente aquí cómo la conjunción de los verbos ह̌̃ $\varepsilon \rho \psi \varepsilon$ (deleitar) y ह̌́ $\pi \varepsilon 1 \sigma \varepsilon$ (persuadir) fusiona la finalidad retórica del género epideíctico, deleitar, con la función persuasiva de los discursos forenses. ${ }^{12}$ Incluso, esa tesis puede considerarse verdadera para el propio Encomio de Helena, texto epidíctico con marcada influencia de defensa judicial, que con téchne argumentativa nos convence de la irresponsabilidad absoluta de la espartana en los hechos que la involucran.
} 
instancias se desliga del discurso del héroe quien está, como corresponde al héroe trágico, en la soledad más absoluta con su conocimiento. Esa lectura convierte a la Defensa en una expresión desgarrada de apología de la verdad que pone en escena la pérdida de confianza en la argumentación y la persuasión como caminos que garanticen el acceso a la justicia, la equidad y al triunfo de los valores superiores en la convivencia entre los hombres. Detrás de la ironía trágica del Palamedes y de su ideal de verdad, la pieza gorgiana se proyecta hacia sus con-textos, y revela las voces plurales, complementarias, apologéticas, trágicas, irreconciliables, todas verdaderas, que se desprenden de la enunciación de ese yo.

\section{REFERENCIAS}

ÁLVAREZ, L. La sofística y su enfoque performativo de la pólis ateniense. Apariencia, visión y mirada del otro en Protágoras, Antifonte y Gorgias. Tesis de Maestría. Facultad de Filosofía y Letras. Buenos Aires: Universidad Nacional de Buenos Aires, 2014.

CASSIN, B. (ed.) Positions de la sophistique. Paris: Vrin, 1986.

CASSIN, B. L'effet sophistique. Paris: Éditions Gallimard, 1995.

CASTELLO, L.; MÁRSICO, C. (eds.) El lenguaje como problema entre los griegos ¿ Como decir lo real? Buenos Aires: GEA, 2005.

CHIALVA I.; BONACOSSA, M.; CASÍS, M. N.; OMAR, M. L. Gorgias. Encomio de Helena. Santa Fe: Ediciones UNL, 2013.

CLÚA SERENA, J.A. Plutarco (Quaest. Conviv. IX, 1-3), los trágicos griegos y Filóstrato en torno al origen del arte de la escritura. In SANTANA HENRÍQUEZ, G. (ed.). Plutarco y las artes. Madrid: Ediciones Clásicas, 2013, p. 129-138.

CLÚA SERENA, J. A. El mite de Palamede a la Grécia Antiga: aspectos canviants d'un interrogant cultural i històric. Faventia, v. 7, n. 2, p. 69-93, 1985.

CONSIGNY, S. Gorgias, Sophist and Artist. Columbia: University of South Carolina Press, 2001.

DAVOLIO, M.; MARCOS, G. Gorgias. Encomio de Helena. Buenos Aires: Ediciones Winograd, 2011.

FERNÁNDEZ DELGADO, J.A.; PORDOMINGO, F. ¿Qué palabras diría Electra a la vista del cadáver de Egisto? (E. El. 907-956). In: LÓPEZ FÉREZ, J. A. et al. (eds.).

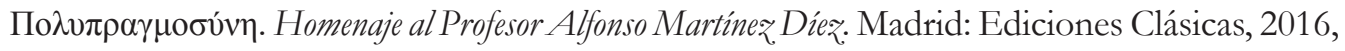
p. 211-218.

DÍAZ M. E. y SPANGENBERG, P. Gorgias. Sobre el No Ser. Buenos Aires: Ediciones Winograd, 2011.

EVEN-ZOHAR, I. The position of Translated Literature within the Literary Polysystem. Polysystem Studies, v. 11, n. 1, p. 45-51, 1990.

GAGARIN, M. “On the Not-Being of Gorgias's 'On Not-Being”. Philosophy \& Rhetoric, v. 30, n. 1, p. 38-40, 1997. 
GAGARIN, M. "Did the sophists aim to persuade? Rhetorica: A Journal of the History of Rhetoric, v. 19, n. 3, p. 275-91, 2001.

GAGARIN, M. Socrates and Antiphon: Intellectuals on trials in classical Athens”. In Melanges en l'honneur Panayotis D. Dimaks. Droits antiques et société. Athénes: Éditions Ant. N. Sakkoulas, 2002, p. 397-404.

GIOMBINI, S. Gorgia epidittico. Commento filosofico all Encomio di Elena, all'Apologia di Palamede, all' Epitaffio. Passignano sul T.: Aguaplano, 2012.

LIVOV, G.; SPANGENBERG, P. (eds.). La palabra y la ciudad. Retórica y política en la Grecia Antigua. Buenos Aires: La bestia equilátera, 2012.

MARTINEZ, J. T. A defesa de Palamedes e sua articulação com o Tratado sobre o não ser de Gorgias. Campinas: Unicamp, 2008. Sitio web: <http://www.bibliotecadigital.unicamp.br/ document $/$ ?code $=$ vtls000437096\&opt $=4>$.

MAZZARA, G. Gorgia. La Retorica del Verísimile. Hardcover: Academia Verlag. Sankt Augustin, 1999.

McCOMISKEY, B. Gorgias and the New Sophistic Rhetoric. Carbondale: Southern Illinois University Press, 2002.

ROMERO MARISCAL, L. Sófocles y el mito de Palamedes. Pensamiento y tragedia en el siglo V a.C. In: PÉREZ JIMÉNEZ, A.; ALCALDE MARTÍN, C. y CABALLERO SÁNCHEZ, R. (eds.). Sófocles el hombre. Sófocles el poeta. Málaga: Ed. Málaga, 2004, p. 217-231.

ROMERO MARISCAL, L. El prólogo del Palamedes de Eurípides. Lexis. Poetica, Retorica e Communicazione nella Tradizione Classica, v. 25, p. 229-240, 2007.

ROMERO MARISCAL, L. Sobre la identidad del coro del Palamedes de Eurípides. In NIETO IBÁNEZ, J. M. (ed.). Lógos hellenikós. Homenaje al profesor Gaspar Morocho Gayo. León: Universidad de León, 2003, v. 1, p. 405-410.

de ROMILLY, J. Les grands Sophistes dans l'Athènes de Périclès. Paris: Éditions de Fallois, 1988.

UNTERSTEINER, M. Sofisti. Testimonianze e Frammenti. Fascicolo secondo: Gorgia, Licofrone e Prodico, Firenze: La nouva Italia, 1967 [1949].

UNTERSTEINER, M. I Sofisti. Roma: Bruno Mondadori, 2008 [1967].

VELLAY, CH. La Palamédie. Bulletin de l'Association Guillaume Budé, v. 2, p. 55-67, 1956.

WARDY, R. The birth of Rethoric. Gorgias, Plato and their successors. New York: Routledge, 1996.

WOODFORD, S. Palamedes Seeks Revenge. Journal of Hellenic Studies, v. 114, p. 164-169, 1994.

WORTHINGTON, I. Persuasion: Greek Rhetoric in Action. London, New York: Routledge, 1994.

WORTHINGTON, I. A Companion to Greek Rhetoric. Oxford: Blackwell Publishing, 2007.

Recebido em: 30 de novembro de 2016 Aprovado em: 20 de fevereiro de 2017 